\section{THE IMPACT OF COVID 19 ON PAEDIATRIC TYPE 1 DIABETES AND DKA PRESENTATIONS IN A PERIPHERAL HOSPITAL IN IRELAND}

Irina Chistol*, Livija Ceher-Ebner, Conor Moloney, Niall O'Brien, Deidre Bowers, Maybelle Wallis, Attia Kalim. Wexford General Hospital

\subsection{6/archdischild-2021-europaediatrics.215}

The purpose of our study was to identify any change in the presentation rates of children with type 1 diabetes or diabetic ketoacidosis (DKA) to our hospital during the first wave of the Covid 19 pandemic.

In Ireland, the first case of Covid 19 was reported on the 29th of February 2020. Schools were closed on the 1st of March 2020. Initial restrictions were implemented on the 15th of March 2020 and the first lockdown spanned from the 27th of March to the 18th of May 2020, while the second one lasted from the 15 th of September to the 1 st of December 2020 (1).

We retrospectively studied presentations of children with diabetes and DKA to our hospital, which serves the population of County Wexford, Ireland, during the first 7 months of the Covid 19 pandemic from the 18th of March 2020 to the 30 th of November 2020, comparing them to presentations in the same months of the previous year, 2019. We extracted data from the hospital Diagnosis Related Groups (DRG) database.

All children with type 1 diabetes who were admitted to the hospital through emergency department (ED) including those who presented with DKA and were managed as per HSE DKA guidelines (2) were included in our study. We did not include children with diabetes who attended the ED but were not admitted.

Admissions of children 1929 (2019) 714 (2020)

Admissions of children due to diabetes: 19 (2019) 15 (2020)

Admissions of children with diabetes, not DKA 12 (2019) 9 (2020)

Admissions of children in DKA 7 (2019) 6 (2020)

A decline in non-covid related admissions had been noted in many healthcare facilities. (3) In our Paediatric department there was a sharp decrease in the number of childhood admissions during the Covid 19 pandemic. Although the absolute numbers were similar, the proportion of admissions related to diabetes including DKA showed an upward trend during the pandemic in our hospital with the relative risk of 2.14 and the odds ratio of 2.16 .

A change in the pattern of utilisation of health care and altered diabetes presentation has also been reported in other studies. (4,5) Covid 19 related stress, isolation, transport restrictions, post viral onset and changes in the life style may have been contributing factors.

\section{DISCREPANCY BETWEEN CLINICAL PRESENTATION AND SEX STREROID HORMONE VALUES IN A PREPUBERTAL GIRL}

Lavinia La Grasta Sabolić*, Marija Požgaj Šepec, Ivana Zec, Dario Mandić, Gordana Stipančić. Sestre milosrdnice University Hospital Center, Zagreb, Croatia

10.1136/archdischild-2021-europaediatrics.216

Background Laboratory evaluation is crucial for accurate assessment of patients with endocrine disorders. When clinical picture is in obvious contradiction with laboratory results, one should suspect and prove analytical interference.

Case presentation: a 6.7-year-old girl presented with sexual and axillary hair accompanied by adult-type body odor. She was tall (height SDS 2.6), with no other signs of virilisation and no breast development. Her bone age was slightly advanced (7.5 years), and laboratory workup showed markedly elevated levels of dehydroepiandrosterone sulphate (DHEAS), elevated testosteron and appropriate level of 17-hydroxyprogesterone (17-OHP) measured by electrochemical luminescence immunoassay (ECLIA). Subsequent investigations confirmed previous laboratory results, but also revealed elevated serum estradiol with no evidence of estrogen effect on uterus and no adrenal or adnexal mass. Cortisol level was unremarkable. During one year folow up, there were no changes in girl's clinical appearance, while levels of her sex steroids determined by ECLIA fluctuated from undetectable or slightly elevated to markedly elevated. There were no apparent risk factors for analytic interference (no biotin supplementation or drugs, negative rheumatoid factor, no hypergammaglobulinemia). When samples were reanalyzed with the addition of a blocking agent, significantly lower levels of serum sex steroids were obtained, while liquid chromatography tandem mass spectrometry (LC-MS/MS) revealed sex steroids appropriate for age.

Conclusion Laboratory interference is a drawback in hormonal testing.

Clinicians should have that in mind when faced with laboratory results discordant with patient's clinical presentation. Elevation of multiple sex steroid hormones in a prepubertal girl due to laboratory interference in immunoassay was finally unmasked by LC-MS/MS.

\section{HYPEROSMOLAR HYPERGLYCEMIC STATE IN A 7-YEAR- OLD BOY WITH NEWLY DIAGNOSED TYPE 1 DIABETES MELLITUS}

Ivona Butorac Ahel*, Srećko Severinski, Ana Milardović, Marija Bandić. Clinical Hospital Center Rijeka

\subsection{6/archdischild-2021-europaediatrics.217}

Hyperglycemic hyperosmolar state (HHS) is characterized by severe hyperglycemia and hyperosmolality without significant ketosis and acidosis. Although the incidence of HHS is increasing, it is considerably less frequent in children than diabetic ketoacidosis (DKA). We report a rare case of HHS as the first presentation of type 1 diabetes mellitus (T1DM) in a 7-year-old boy with previously diagnosed Joubert syndrome (JS). He presented to the emergency room with a 3-day history of vomiting. The symptoms of polydipsia and polyuria started several days earlier. On the day of admission he had been drinking an excess of beverages rich in sugars (approximately $800-900 \mathrm{ml} /$ day). At admission he was tachypnoic, normotensive and moderately dehydrated. It was difficult to assess his mental and neurological status because of JS, but his mother claimed that he was acting normally. Initial biochemistry results demonstrated severe hyperglycemia $(115 \mathrm{mmol} / \mathrm{l})$, hyperosmolality of $382 \mathrm{mOsm} / \mathrm{kg}$ (effective osmolality 353 $\mathrm{mOsm} / \mathrm{kg}$ ), mild acidosis (venous $\mathrm{pH}$ 7.31), hyponatremia (sodium $119 \mathrm{mmol} / \mathrm{l}$; corrected for blood glucose: $138 \mathrm{mmol} /$ $\mathrm{L})$, severe glycosuria, and ketones in urine were negative. The diagnosis of HHS was made and the treatment with intravenous fluid was started and insulin administration begun later. 